\title{
Self-medication and knowledge among pregnant women attending primary healthcare services in Malang, Indonesia: a cross-sectional study
}

\author{
Rizka Novia Atmadani ${ }^{1,2}$, Owen Nkoka², Sendi Lia Yunita ${ }^{1,2}$ and Yi-Hua Chen ${ }^{2 *}$
}

\begin{abstract}
Background: Self-medication with over-the-counter (OTC) drugs is an important public health concern, especially in the vulnerable population of pregnant women due to potential risks to both the mother and fetus. Few studies have studied how factors, such as knowledge, affect self-medication. This study investigated self-medication and its associated factors among pregnant women attending healthcare services in Malang, Indonesia.

Methods: A cross-sectional study was conducted from July to September 2018 in five healthcare services. A selfadministered questionnaire was used and the data were analyzed using multiple regression models.

Results: Of 333 female participants, 39 (11.7\%) used OTC medication. Women with a higher level of knowledge of OTC medication were more likely to self-medicate-adjusted odds ratio $(\mathrm{aOR})=2.15,95 \%$ confidence interval $(\mathrm{Cl})=$ 1.03-4.46. Compared with those with less knowledge, pregnant women with more correct knowledge of the possible risk of self-medication were less likely to self-medicate- $\mathrm{aOR}=0.29 ; 95 \% \mathrm{Cl}=0.14-0.60$. The effect of a higher level of knowledge of OTC medication was significant among women who had middle school and lower education-aOR $=8.18 ; 95 \% \mathrm{Cl}=1.70-39.35$. The effect of correct knowledge on the possible risks of selfmedication was significant only among women with high school and higher education- $\mathrm{aOR}=0.17 ; 95 \% \mathrm{Cl}=0.07-$ 0.42 .

Conclusion: Imparting specific knowledge of the potential risks of using non-prescribed medication during pregnancy may help pregnant women navigate and more safely manage their OTC use. We also suggest further collecting data from more healthcare services, such as hospitals, to obtain more findings generalizable to the Indonesian community.
\end{abstract}

Keywords: Pregnancy, Over-the-counter medication, Knowledge, Healthcare service, Indonesia

\section{Background}

The use of medication during pregnancy is a public health concern. Globally, almost $50 \%$ of pregnant women use medication in the early weeks of gestation [1]. Using a web-based multinational study, Lupattelli et al. discovered that $81.2 \%$ of pregnant women used at least one type of medication, either prescribed or over-

\footnotetext{
* Correspondence: yichen@tmu.edu.tw

${ }^{2}$ School of Public Health, College of Public Health, Taipei Medical University, Taipei, Taiwan

Full list of author information is available at the end of the article
}

the-counter (OTC) [2]; over 65\% self-medicated with OTC medication.

Self-medication, particularly with OTC medication, is considered a potential for harm for pregnant women [35]. The United States Food and Drug Administration's (FDA's) 1979 regulations categorized drugs by pregnancy risk. There are five categories, each marked by a letter: A, B, C, D, or X [6]. Only a few OTC medications or prescription drugs are of category A or B (indicating no evidence of risk to the fetus), whereas many drugs are of category $\mathrm{C}$ (indicating evidence of potential benefits

(c) The Author(s). 2020 Open Access This article is distributed under the terms of the Creative Commons Attribution 4.0 International License (http://creativecommons.org/licenses/by/4.0/), which permits unrestricted use, distribution, and reproduction in any medium, provided you give appropriate credit to the original author(s) and the source, provide a link to the Creative Commons license, and indicate if changes were made. The Creative Commons Public Domain Dedication waiver (http://creativecommons.org/publicdomain/zero/1.0/) applies to the data made available in this article, unless otherwise stated. 
outweighing potential fetal risks), or of categories D or $\mathrm{X}$ (indicating evidence of fetal risk) [7].

Indeed, medication use during pregnancy is a dilemma because the vulnerable population (i.e., pregnant women and children) is not included in clinical drug trials $[8,9]$. Therefore, there is not enough data of the effects from such medicine on the vulnerable groups. One such study discovered an association between a pregnant woman's use of aspirin and intracranial hemorrhage in her newborn baby [10]. Another study discovered an association between a pregnant woman's use of valproic acid and the risk of neural tube defects in her fetus [11]. In general, studies on the fetal effects of self-medication are limited because of the complexity of the examination [12].

Despite the dilemma, prenatal self-medication is reportedly frequent. Studies on self-medication have reported its varying prevalence due to different study populations, design, and socio-cultural contexts. For instance, self-medication was reported among $12.5 \%$ of pregnant women in a study conducted in Netherlands [13], whereas a higher rate of $40 \%$ during pregnancy was reported by another study conducted in the United Arab Emirates [14]. In addition, there were inconsistent findings of the effect of different factors on self-medication during pregnancy from other studies [12, 15]. Studies concluded that factors such as one's knowledge, beliefs, and socio-demographic background are associated with self-medication during pregnancy [16-21]. For instance, in studies conducted in Ethiopia and Italy, pregnant women with more knowledge of the risks of selfmedication were less likely to self-medicate, compared with those with less knowledge [19, 22]. However, studies investigating about the knowledge of potential risk effects of those medications on the fetus are scarce.

In Indonesia, OTC medicines are readily available in drug stores, retail stores, or kiosks [23]. Previous studies have investigated self-medication in the Indonesian population, but they did not focus on prenatal usage [24]. Moreover, there is scant information in the literature on how a pregnant woman's knowledge of OTC medication and her beliefs on the use of medication affects their practice of self-medication.

Due to self-medication's potential for harm to both the mother and fetus, it is therefore imperative to study the prevalence of self-medication and factors associated with self-medication during pregnancy. In addition, such a study ought to focus on the factors of a pregnant woman's knowledge of OTC medication and beliefs on the use of medication. Findings from such studies will help public health practitioners appraise the importance of a woman's knowledge of the use of OTC medication. An appraisal will help in the formulation of health education programs to assist women in realizing how to safely manage their
OTC use during pregnancy. For Indonesia in particular, although self-medication use for the general population has been investigated, the examination of the use during critical periods of women's pregnancy has been lacking. Findings from those studies would be vital for tailor-made interventions to promote the safe use of medication during pregnancy for maternal and fetal health. Furthermore, it is important to examine effect modifiers between the relationship of knowledge of OTC medication with the practice of self-medication. Some examinations are helpful in the identification of high-risk groups with regard to self-medication during pregnancy.

Therefore, this study aims to examine (1) the proportion of pregnant women who self-medicated in this convenience sample in Malang, Indonesia; (2) the factors associated with the practice of self-medication during pregnancy; and (3) the moderating effects of sociodemographic characteristics on the relationship between knowledge of OTC medication and the practice of selfmedication during pregnancy.

\section{Methods \\ Study area}

This study was conducted in Malang City and Malang Regency, Java, Indonesia. Malang Regency is the largest regency in East Java province. In 2017, its population was approximately $2,576,596$ [25] and the population of Malang City was approximately 861,414 [26].

\section{Samples and data collection}

This cross-sectional study was conducted from July to September 2018 at five primary healthcare services (Puskesmas, also called public health center) in Malang. Three healthcare services are located in the southeast area of Malang Regency, and two are located in the center of Malang City. A convenience sampling method was adopted. All pregnant women coming to the Puskesmas and queuing to see a healthcare provider (either a midwife or doctor) were eligible for inclusion in this study. Pregnant women who were unable to read or speak the language of Bahasa Indonesia were excluded from the survey as the data collection instrument was administered in this local language. Approximately $80 \%$ of pregnant women agreed to participate in this survey among those who accessed care at that time. The questionnaires were self-administered in the waiting room at each of the healthcare service. They were collected on-site immediately after the questionnaires were completed. Upon completion, the interviewer checked the questionnaire and asked the respondent to review their responses if there were missing items.

The formula by Kish and Leslie (1965) was used for sample size calculation. With the use of previous data that $25 \%$ of pregnant women used OTC medication [27] 
and a 5\% margin of error was expected, the sample size required for this study was 321 participants.

\section{Questionnaire development}

A structured self-reported questionnaire was developed to assess pregnant women's (1) health and pregnancy condition (pregnancy status, health condition, and health behavior), (2) knowledge of OTC medication during pregnancy, (3) beliefs about medication use during pregnancy, and (4) socio-demographic characteristics. The questionnaire was originally developed in English (Additional file 1) and translated into Bahasa Indonesia. For the evaluation of the content, semantics, and conceptual equivalence of the instruments in both the source and target languages, translation, back-translation, expert review and a pilot study was recommended by Guillemin et al. (1993) as guidelines for cross-cultural adaptation of health-related measures. The questionnaire utilized in this study was developed based upon these guidelines [28].

To translate the English instrument into Bahasa Indonesia version, we performed a forward and backward translation. First, a bilingual expert who was fluent in both English and Bahasa Indonesia translated the English version to Bahasa Indonesia. Another expert from a language center in Indonesia then back translated to English to ensure consistency of meaning. Then, two additional experts independently compared the original English instrument and the version translated back from Bahasa Indonesia to certify the equivalence and cultural relevance. An overall agreement was achieved. In addition, the instrument utilized was edited and modified based upon expert review. Four experts in pharmacy, public health, and epidemiology fields comprehensively reviewed the scope of this study and examined the content validity of the questionnaire in April, 2018. A pilot study was then conducted among 20 pregnant women [29] in May 2018 to assess practicability and face validity. This pilot study certified women's understanding and feasibility of implementation. Minor modifications of the wording of the questions were further performed to ensure easier comprehension based upon experts' evaluation.

\section{Outcome variable}

The outcome measure was "self-medication" (specifically, of OTC medication) assessed by asking whether the pregnant women had used at least one type of OTC medication in their current pregnancy. They answered either yes or no.

\section{Independent variable}

A pregnant woman's knowledge of OTC medication, the main independent factor of this study, was evaluated relative to items generated from a literature review, yielding a total of 12 knowledge statements that was validly used previously [22, 30]. In our study, content validity index (CVI) calculated from expert review was utilized to quantify content validity. Based upon expert opinions along with CVI values over 0.8 , all 12 questions were retained. Questions were further edited based upon the experts' opinions. The Cronbach's alphas for the questions on knowledge of OTC medication during pregnancy were 0.88 and 0.85 in the pilot study and in the final enrolled sample, respectively, indicating appropriate internal consistency.

Assessments of pregnant women's knowledge of OTC medication involved statements such as "There are possible risks from the use of OTC medication during pregnancy" and "There is a need to consult a healthcare provider before taking OTC medication." Each statement was accompanied by three possible responses: "yes," "no, " and "do not know." Items answered correctly were coded as "1" and items answered incorrectly (including those having the response "do not know") are coded as "0." These were summed into a knowledge score. As there were 12 statements, the knowledge scores ranged from 0 to 12 . We used these total knowledge scores to estimate the change in the likelihood of self-medication per unit of change in knowledge.

In addition, we investigated whether women having knowledge above a certain level behaved differently in terms of OTC medication. We thus used the third quartile as a cut-off point to categorize knowledge scores into two ("high level of knowledge" and "low level of knowledge") subcategories [31]. We also separately analyzed the two important questions/statements in the knowledge section of "Knowledge about the need to consult any healthcare provider" and "Knowledge about possible risk from taking OTC medication during pregnancy" to emphasize on the crucial and specific medication understanding of consultation with healthcare provider and possible risks during pregnancy.

\section{Other covariates}

A pregnant woman's beliefs regarding medication during pregnancy was measured using nine questions (six for medication and three for natural remedies usage) adopted from previously validated surveys in Norway [32], Saudi Arabia [33] and Belgium [34]. In our study, all nine questions were retained based upon experts' evaluation and CVI values larger than 0.8 , with minor editing performed corresponding with experts' opinions. The Cronbach's alphas were 0.82 and 0.7 in the pilot study and in the final enrolled sample, respectively, to indicate acceptable internal consistency. For the assessment of woman's beliefs regarding medication during pregnancy in the first six questions, each question had a five-point Likert scale ranging from "strongly disagree" to "strongly agree." The sum of the scores ranged from 6 
to 30. This sum measured the level of a pregnant woman's belief toward taking medication during pregnancy, with lower scores indicating a more positive belief. The first quartile was used as a cut-off point to categorize belief scores into two ("positive" and "negative") subcategories.

Data on socio-demographic characteristics were also gathered. Two- and three-level variables were used. Two-level variables included gestational age (first vs. second and third trimesters), age (16-27 vs. $28-45$ years), parity ( 0 vs. 1 or more children), education level (middle school and lower vs. high school and higher), number of antenatal care (ANC) visits (fewer than 4 vs. 4 or more), household income (fewer than 1.5 million Rupiah vs. 1.5 million Rupiah or more), and residence (urban vs. rural). Three-level variables included occupation (student, homemaker, and employed) and health behavior with regard to reading a drug's accompanying leaflet (always, sometimes, and never).

\section{Statistical analysis}

Data were entered and analyzed using SPSS version 18 (SPSS, Chicago, IL, USA). We used the chi-square tests and Fisher's exact tests to analyze differences in sociodemographics (e.g., age, education), pregnancy related variables (e.g., number of ANC visits), health related variables (e.g., self-perceived heath status, checking drug leaflet), and knowledge on OTC medication in relation to self-medication. The variables that had been reported previously to potentially confound the association examined or were possibly related to main independent and outcome variables using simple logistic regression models $(p \leq 0.25)$ were considered for multivariable regression models selection [22, 35]. Logistic regression using the "enter method" with all potential covariates simultaneously included for consideration was performed for final model selection. All factors were reported with their crude and adjusted odds ratios (aORs) and their $95 \%$ confidence intervals (CIs). A $p$ value of $<$ 0.05 was considered statistically significant.

We also examined the interaction between knowledge and socio-demographic characteristics with the likelihood of self-medication. An interaction $p$ value of $<0.1$ [36] was used to indicate potential moderation effects and the warranting of further subgroup analyses.

\section{Ethical considerations}

The Commission of Research Ethics of the University of Muhammadiyah Malang (E.5.a/226a/KEPK-UMM/VII/ 2018) provided ethical approval. Informed consent was sought from each respondent about the details of the study's background, objectives, and providing information on the protection of the participant's data. All respondents signed a written informed consent.

\section{Results}

\section{Socio-demographic characteristics}

In total, 340 respondents were enrolled for participation. After excluding those with missing or incomplete information on main variables, a valid sample of 333 women was included for analyses. Most participants were aged 16-27 years (54.4\%), had attended high school or institutes of higher education (70.3\%), had adequate ANC visits (68.5\%), and were homemakers (72.1\%) (Table 1).

\section{Self-medication during pregnancy}

In total, $39(11.7 \%)$ women self-medicated at least once during pregnancy. During pregnancy, the OTC medications used included antiemetic medicines (33\%), cold and flu remedies (29\%), anti-fever medication (15\%), pain killers (13\%), and others (10\%). Among those who self-medicated during pregnancy, approximately 10.3\% did so in their first trimester. No significant difference was observed in socio-demographic characteristics between those who self-medicated and those who did not (Table 1).

\section{Knowledge of OTC medication}

Of the 12 statements measuring knowledge of OTC medication, 6 were answered correctly by over $60 \%$ of participants. The statement having the highest proportion $(86.2 \%)$ of correct responses is "You need to consult with healthcare provider before or when taking OTC medication during pregnancy," and the statement having the lowest proportion (28.8\%) of correct responses is "Antibiotics is one of OTC medication" (Table 2). Table 2 lists the proportion of different knowledge responses segmented by self-medication. Women who took at least one OTC medication during pregnancy were more likely to correctly answer the statements "Vitamin is one of OTC medication" (79.5\%) and "OTC medication can be in the dosage form of oral medication" (92.3\%). By contrast, these women were more likely to incorrectly answer the statement "While taking OTC medication there is possible risk that OTC drugs can affect the baby" (59.0\%).

\section{Beliefs about taking medication during pregnancy}

Respondents' beliefs about taking medication during pregnancy are presented in Table 3. They generally expressed negative belief toward medication use during pregnancy. A majority of respondents agreed with the following statements. "Pregnant women have a higher threshold for using medicine when pregnant than when not pregnant." (84.1\%). "It is better for the fetus that pregnant women refrain from using medicines during pregnancy, even when they were not pregnant and have an illness, they would have taken medicines." (61.3\%). "It is better for the fetus if the mother takes medicines and 
Table 1 Distribution of participants by self-medication

\begin{tabular}{|c|c|c|c|c|c|}
\hline \multirow[t]{2}{*}{ Variables } & \multirow{2}{*}{$\begin{array}{l}\text { Total } \\
(n= \\
333)\end{array}$} & \multirow[t]{2}{*}{$\%$} & \multicolumn{2}{|c|}{ Self-medication } & \multirow[t]{2}{*}{$p$ value } \\
\hline & & & $\begin{array}{l}\text { Yes } \\
\text { n (\%) }\end{array}$ & $\begin{array}{l}\text { No } \\
\text { n (\%) }\end{array}$ & \\
\hline Self-medication in current pregnancy & & & $39(11.7)$ & $294(88.3)$ & \\
\hline Gestational age (trimester) & & & & & 0.470 \\
\hline First trimester & 37 & 11.1 & $4(10.3)$ & 33(11.2) & \\
\hline Second \& Third trimester & 296 & 88.9 & $35(89.7)$ & $261(88.8)$ & \\
\hline Age & & & & & 0.075 \\
\hline $16-27$ & 181 & 54.4 & $16(41.0)$ & $165(56.1)$ & \\
\hline $28-45$ & 152 & 45.6 & $23(59.0)$ & $129(43.9)$ & \\
\hline Parity & & & & & 0.137 \\
\hline 0 & 148 & 44.4 & $13(33.3)$ & $135(45.9)$ & \\
\hline 1 or more children & 185 & 55.6 & $26(66.7)$ & $159(54.1)$ & \\
\hline Education level & & & & & 0.880 \\
\hline Middle school or lower & 99 & 29.7 & $12(30.8)$ & $87(29.6)$ & \\
\hline High school or higher & 234 & 70.3 & $27(69.2)$ & $207(70.4)$ & \\
\hline Number of ANC Visits & & & & & 0.174 \\
\hline$<4$ & 105 & 31.5 & $16(41.0)$ & $89(30.3)$ & \\
\hline$\geq 4$ & 228 & 68.5 & $23(59.0)$ & $205(69.7)$ & \\
\hline Occupation & & & & & 0.901 \\
\hline Student & 14 & 4.2 & $2(5.1)$ & $12(4.1)$ & \\
\hline Homemaker & 240 & 72.1 & $27(69.2)$ & $213(72.4)$ & \\
\hline Employed & 79 & 23.7 & $10(25.6)$ & $69(23.5)$ & \\
\hline Household Income & & & & & 0.897 \\
\hline$<1.5$ Million Rupiah & 159 & 47.7 & $19(48.7)$ & $140(47.6)$ & \\
\hline 1.5 Million Rupiah or more & 174 & 52.3 & $20(51.3)$ & $154(52.4)$ & \\
\hline Residence & & & & & 0.174 \\
\hline Urban & 243 & 73.0 & $32(82.1)$ & $211(71.8)$ & \\
\hline Rural & 90 & 27.0 & $7(17.9)$ & $83(28.2)$ & \\
\hline Self-perceived Health Status & & & & & 0.997 \\
\hline Good & 239 & 71.8 & $28(71.8)$ & $211(71.8)$ & \\
\hline Bad & 94 & 28.2 & $11(28.2)$ & $83(28.2)$ & \\
\hline Checking drug leaflet & & & & & 0.510 \\
\hline Always & 184 & 55.3 & $19(48.7)$ & $165(56.1)$ & \\
\hline Sometimes & 117 & 35.1 & $17(43.6)$ & $100(34.0)$ & \\
\hline Never & 32 & 9.6 & $3(7.7)$ & 29 (9.9) & \\
\hline
\end{tabular}

${ }^{a} p$ value from chi square tests and Fisher's exact test

get well than having untreated illness during pregnancy." (63.1\%). By contrast, $56.5 \%$ of the sampled women disagreed with the statement "All medicines can be harmful to the fetus."

\section{Factors associated with self-medication}

Table 4 reports the results from the multiple logistic regression analysis. Model 1 displays the crude odds ratio. Models 2 to 4 display the effects of knowledge, including the total knowledge score, binary knowledge outcome, and binary outcome of the two aforementioned important pieces of knowledge on selfmedication during pregnancy, after adjusting for sociodemographics. Specifically, Model 2 indicates that the total knowledge score is significantly associated with self-medication-adjusted odds ratio $(\mathrm{aOR})=1.16,95 \%$ $\mathrm{CI}=1.02-1.33$. Including overall knowledge with a binary outcome in Model 3, we observe that women 
Table 2 Knowledge of OTC medication

\begin{tabular}{|c|c|c|c|c|}
\hline \multirow[t]{2}{*}{ Statements } & \multirow{2}{*}{$\begin{array}{l}\text { Total } \\
(n=333) \\
n(\%)\end{array}$} & \multicolumn{2}{|c|}{ Self-medication } & \multirow[b]{2}{*}{$p$ value $^{a}$} \\
\hline & & $\begin{array}{l}\text { Yes } \\
\text { n (\%) }\end{array}$ & $\begin{array}{l}\text { No } \\
\text { n (\%) }\end{array}$ & \\
\hline OTC medications are primarily used to treat condition that do not need direct supervision from doctors & & & & 0.471 \\
\hline Correct & $187(56.2)$ & $24(61.5)$ & $163(55.4)$ & \\
\hline Incorrect & $146(43.8)$ & $15(38.5)$ & $131(44.6)$ & \\
\hline OTC medication is used for treating minor illness/minor injuries & & & & 0.057 \\
\hline Correct & $229(68.8)$ & $32(82.1)$ & $197(67.0)$ & \\
\hline Incorrect & $104(31.2)$ & $7(17.9)$ & $97(33.0)$ & \\
\hline Antibiotic is one of OTC medication & & & & 0.509 \\
\hline Correct & $96(28.8)$ & $13(33.3)$ & $83(28.2)$ & \\
\hline Incorrect & $237(71.2)$ & $26(66.7)$ & $211(71.8)$ & \\
\hline Vitamin is one of OTC medication & & & & 0.003 \\
\hline Correct & 191(57.4) & $31(79.5)$ & $160(54.4)$ & \\
\hline Incorrect & $142(42.6)$ & $8(20.5)$ & $134(45.6)$ & \\
\hline The decision for using OTC medication is primarily made by consumers & & & & 0.162 \\
\hline Correct & $205(61.6)$ & $28(71.8)$ & $177(60.2)$ & \\
\hline Incorrect & $128(38.4)$ & $11(28.2)$ & $117(39.8)$ & \\
\hline You can buy OTC medication without a prescription from a doctor & & & & 0.333 \\
\hline Correct & $234(70.3)$ & $30(76.9)$ & $204(69.4)$ & \\
\hline Incorrect & $99(29.7)$ & $9(23.1)$ & $90(30.6)$ & \\
\hline You can buy OTC medication only in a Pharmacy & & & & 0.900 \\
\hline Correct & $114(34.2)$ & $13(33.3)$ & $101(34.4)$ & \\
\hline Incorrect & $219(65.8)$ & $26(66.7)$ & $193(65.6)$ & \\
\hline You need to consult with healthcare provider before or when taking OTC medication during pregnancy & & & & 0.094 \\
\hline Correct & $287(86.2)$ & $37(94.9)$ & $250(85)$ & \\
\hline Incorrect & $46(13.8)$ & $2(5.1)$ & $44(15)$ & \\
\hline The most dangerous time during pregnancy for consuming OTC medication is the first trimester & & & & 0.408 \\
\hline Correct & $193(58.0)$ & $25(64.1)$ & $168(57.1)$ & \\
\hline Incorrect & $140(42.0)$ & $14(35.9)$ & $126(42.9)$ & \\
\hline While taking OTC medication there is possible risk that OTC drugs can affect the baby & & & & 0.002 \\
\hline Correct & $211(63.4)$ & $16(41.0)$ & $195(66.3)$ & \\
\hline Incorrect & $122(36.6)$ & $23(59.0)$ & $99(33.7)$ & \\
\hline OTC medication can be in the dosage form of oral medication & & & & $<0.001$ \\
\hline Correct & $215(64.6)$ & $36(92.3)$ & $179(60.9)$ & \\
\hline Incorrect & $118(35.4)$ & $3(7.7)$ & $115(39.1)$ & \\
\hline OTC medication can be in the dosage form of topical medication & & & & 0.057 \\
\hline Correct & $143(42.9)$ & $19(48.7)$ & $124(42.2)$ & \\
\hline Incorrect & $190(57.1)$ & $20(51.3)$ & $170(57.8)$ & \\
\hline Knowledge total score (Mean;SD) & $7.0(3.1)$ & $7.8(2.6)$ & $6.8(3.2)$ & $0.070^{b}$ \\
\hline Overall knowledge in binary outcome & & & & 0.087 \\
\hline Lower & $212(63.7)$ & $20(51.3)$ & $192(65.3)$ & \\
\hline Higher & $121(36.3)$ & 19 (48.7) & $102(34.7)$ & \\
\hline
\end{tabular}

${ }^{a} p$ value from chi square tests

${ }^{\mathrm{b}} p$ value from student's t-test

Bold $p$ value means significant (i.e., $p<0.05$ ) 
Table 3 Beliefs on taking medication during pregnancy

\begin{tabular}{lr}
\hline Beliefs on medication in pregnancy & $\begin{array}{c}\text { Total } \\
(n=333) \\
n(\%)\end{array}$ \\
\hline All medicines can be harmful to the fetus ${ }^{\mathrm{a}}$ & $84(25.2)$ \\
Agree & $61(18.3)$ \\
Uncertain & $188(56.5)$ \\
Disagree & 180.5
\end{tabular}

It is better for the fetus that pregnant women refrain from using medicines during pregnancy, even when they were not pregnant and have illness, they would have taken medicines ${ }^{a}$

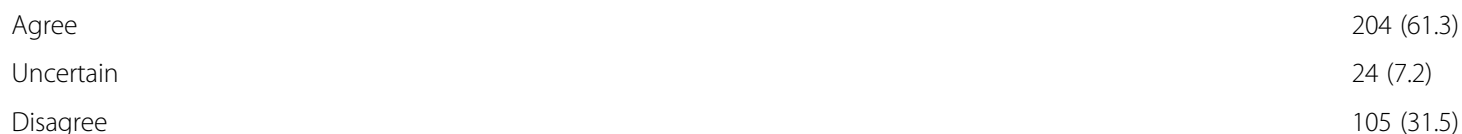

$204(61.3)$

$105(31.5)$

Pregnant women have a higher threshold for using medicine when pregnant than when not pregnant ${ }^{\mathrm{a}}$

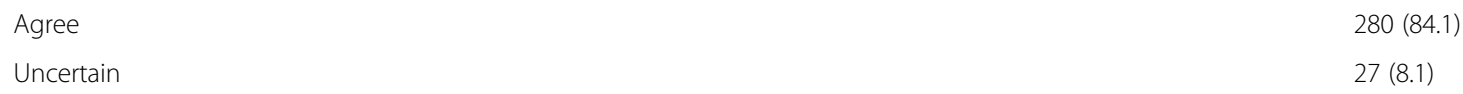

Many unborn children are saved because the mother take medicines during pregnancy when they have illness ${ }^{a}$

Agree

Uncertain

Disagree

It is better for the fetus if the mother take medicines and get well than having untreated illness during pregnancy ${ }^{\mathrm{a}}$

Agree

Uncertain

Disagree

Doctors prescribe too many medicines to pregnant women ${ }^{a}$

Agree

Uncertain

Disagree

Natural remedies can generally be used by pregnant women

Agree

Uncertain

Disagree

Pregnant women more likely to use natural remedies during pregnancy

Agree

Uncertain

Disagree

Pregnant women should not use natural remedies without advices from any health care providers

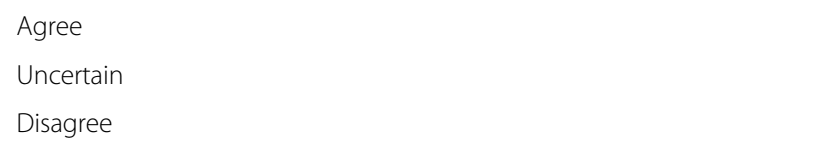

Belief on taking medication during pregnancy (summary index from 6 items)

Negative

Positive
$178(53.5)$

$87(26.1)$

$68(20.4)$

$210(63.1)$

61 (18.3)

62 (18.6)

73 (21.9)

40 (12)

$220(66.1)$

205 (61.6)

67 (20.1)

61 (18.3)

185 (55.6)

67 (20.1)

$81(24.3)$

236 (70.9)

32 (9.6)

65 (19.5)

Percentage

(\%)

78.4

21.6

${ }^{a}$ Statement selected into a 6-item summary index 
Table 4 Multiple logistic regression analysis of knowledge and other factors associated with self-medication during pregnancy

\begin{tabular}{|c|c|c|c|c|}
\hline \multirow[t]{2}{*}{ Variable } & Model $1^{a}$ & Model $2^{b}$ & Model $3^{c}$ & Model $4^{d}$ \\
\hline & cOR $(95 \% \mathrm{Cl})$ & $\mathrm{aOR}(95 \% \mathrm{Cl})$ & $\mathrm{aOR}(95 \% \mathrm{Cl})$ & $\mathrm{aOR}(95 \% \mathrm{Cl})$ \\
\hline \multicolumn{5}{|c|}{ Knowledge of OTC medication (all statements) } \\
\hline Knowledge total score & $1.12(0.99-1.26)$ & $1.16(1.02-1.33)^{*}$ & - & - \\
\hline \multicolumn{5}{|l|}{ Overall knowledge } \\
\hline Lower & 1.00 & - & 1.00 & - \\
\hline Higher & $1.79(0.91-3.50)$ & - & $2.15(1.03-4.46)^{*}$ & - \\
\hline \multicolumn{5}{|c|}{ Knowledge regarding OTC medication with important statements } \\
\hline \multicolumn{5}{|c|}{ Knowledge about the need to consult any healthcare provider } \\
\hline Incorrect & 1.00 & - & - & 1.00 \\
\hline Correct & $3.26(0.76-14.00)$ & - & - & $5.07(1.11-23.2)^{*}$ \\
\hline \multicolumn{5}{|c|}{ Knowledge about possible risk from taking OTC medication during pregnancy } \\
\hline Incorrect & 1.00 & - & - & 1.00 \\
\hline Correct & $0.35(0.18-0.70)^{* *}$ & - & - & $0.29(0.14-0.60)^{* *}$ \\
\hline \multicolumn{5}{|c|}{ Socio-demographic characteristic } \\
\hline \multicolumn{5}{|l|}{ Age } \\
\hline $16-27$ & 1.00 & 1.00 & 1.00 & 1.00 \\
\hline $28-45$ & $1.57(0.80-3.07)$ & $2.20(1.05-4.57)^{*}$ & $2.18(1.05-4.53)^{*}$ & $2.14(1.01-4.50)^{*}$ \\
\hline \multicolumn{5}{|c|}{$\begin{array}{l}\text { OTC over-the-counter, } C O R \text { crude odds ratio, aOR adjusted odds ratio, } C l \text { confident interval } \\
{ }^{a} \text { Crude Model } \\
{ }^{5} \text { Model } 2 \text { included knowledge total scores and all adjusting variables of socio-demographic characteristics (age, gestational age, education, occupation, residence, } \\
\text { and household income), self-perceived health status, and check drug's leaflet } \\
{ }^{c} \text { Model } 3 \text { included overall knowledge (lower vs. higher) and all adjusting variables listed in Model } 2 \\
{ }^{d} \text { Model } 4 \text { included two knowledge statements of "the need to consult any healthcare provider" and "possible risk from taking OTC medication during pregnancy" } \\
\text { and all adjusting variables listed in Model } 2 \\
p \text { value * }<0.05 ; * * 0.01\end{array}$} \\
\hline
\end{tabular}

with a higher level of knowledge of OTC medication were more likely to self-medicate compared with women with lower knowledge-aOR $=2.15,95 \% \mathrm{CI}=$ 1.03-4.46. Results from Model 4 indicate that compared with those who had a lower level of knowledge about the need to consult a healthcare provider before taking OTC medication during pregnancy, pregnant women who had high levels of such knowledge were more likely to self-medicate- $\mathrm{aOR}=5.07,95 \% \mathrm{CI}=$ 1.11-23.2. However, pregnant women who had high levels of knowledge about the possible risks of OTC medication in the fetus were significantly less likely to self-medicate- $\mathrm{aOR}=0.29,95 \% \mathrm{CI}=0.14-0.60$. Additionally, age remains significant in all adjusted models. This indicates that older pregnant women (28-45 years) were significantly more likely to self-medicate$\mathrm{aOR}=2.14,95 \% \mathrm{CI}=1.01-4.50$ (Model 4).

Finally, as both knowledge and belief are important factors, we further estimate the effects of knowledge on self-medication, after considering the effects of belief. The results were fairly consistent. Specifically, knowledge of OTC medication remains significant-aOR = 2.14, 95\% CI $=1.03-4.46$ after controlling for belief and other covariates. Meanwhile, no association was observed between belief and self-medication.

\section{Subgroup analysis for the effects of knowledge on self- medication by socio-demographics}

The interaction terms of binary knowledge with education and binary knowledge with occupation had significant effects on self-medication (both $p<0.1$ ). Subgroup analyses were then performed. Specifically, the effect of a higher level of knowledge on self-medication was significant among women with middle school or lower education-aOR $=8.18, \quad 95 \% \quad \mathrm{CI}=1.70-39.35$-but not among women with high school or higher education (Table 5). Furthermore, the effect of knowledge of the possible risks of taking OTC medication during pregnancy on self-medication was significant only among women with high school or higher education-aOR = 0.17, 95\% CI $=0.07-0.42$ (Table 5). The moderation effects of occupation on the association between knowledge of possible risks and self-medication were not significant.

\section{Discussion}

This study aimed to investigate first, the proportion of pregnant women self-medicated in this collected sample and factors associated with self-medication and second, the potential moderation effects of socio-demographic characteristics. This study focused on pregnant women 
Table 5 Subgroup analysis for effects of knowledge on self-medication by socio-demographics

\begin{tabular}{|c|c|c|c|c|}
\hline \multirow[t]{3}{*}{ Outcomes } & \multicolumn{2}{|l|}{ Education } & \multicolumn{2}{|l|}{ Occupation } \\
\hline & $\begin{array}{l}\text { Middle school and } \\
\text { lower }\end{array}$ & $\begin{array}{l}\text { High school and } \\
\text { higher }\end{array}$ & Homemaker & Employed \\
\hline & aOR $(95 \% \mathrm{Cl})$ & aOR $(95 \% \mathrm{Cl})$ & $\begin{array}{l}\mathrm{aOR}(95 \% \\
\mathrm{Cl})\end{array}$ & $\begin{array}{l}\mathrm{aOR}(95 \% \\
\mathrm{Cl})\end{array}$ \\
\hline Higher level of knowledge ${ }^{a}$ & $\begin{array}{c}8.18 \\
(1.70-39.35)^{* *}\end{array}$ & $\begin{array}{c}1.23 \\
(0.53-2.86)\end{array}$ & $\begin{array}{l}3.02 \\
(1.18-7.70)^{*}\end{array}$ & $\begin{array}{l}0.67 \\
(0.15-3.04)\end{array}$ \\
\hline $\begin{array}{l}\text { Correct knowledge of risks of taking OTC medication during } \\
\text { pregnancy }\end{array}$ & $\begin{array}{c}1.09 \\
(0.28-4.20)\end{array}$ & $\begin{array}{c}0.17 \\
(0.07-0.42)^{* * *}\end{array}$ & - & - \\
\hline
\end{tabular}

OTC over-the-counter, $a O R$ adjusted odds ratio, $\mathrm{Cl}$ confident interval

$p$ value ${ }^{*}<0.05 ;{ }^{* *}<0.01 ;{ }^{* * *}<0.001$

${ }^{a}$ Knowledge was categorized into two levels: higher and lower. Results were adjusted for socio-demographic variables (such as age, gestational age, self-rated health status, education, occupation, household income, and residence) excluding variables treated as the effect modifier

${ }^{b}$ Knowledge was categorized into two levels: correct and incorrect answer. Results were adjusted for socio-demographic variables (such as age, gestational age, occupation, self-rated health status, household income, and residence)

attending primary healthcare services in Malang, Indonesia. A higher level of knowledge was associated with a higher likelihood of self-medication during pregnancy. However, if women had knowledge of the risks from OTC medication, they were less likely to selfmedicate. The effects of a higher level of knowledge on higher self-medication were significant among women with middle school or lower education, whereas the correct knowledge of potential risk effects was associated with a lower likelihood of self-medication among women with high school or higher education.

The proportion of self-medication during pregnancy in our sample was observed to be low (11.7\%). Our findings were similar to those of studies conducted in the Netherlands (12.5\%) [13], Nigeria (22.3\%) [37], and Saudi Arabia (13.2\%) [33]. The proportion in this study is however lower than that (40\%) observed by a study conducted in the United Arab Emirates [14]. A US study reported that self-medication is common [12]. It is likely that pregnant women in Malang have more knowledge of the risks of taking OTC medication during pregnancy. This is evident in the high proportion of correct response for the statement such as "While taking OTC medication there is possible risk that OTC drugs can affect the baby" (63.4\%). These findings are consistent with those of a study conducted in Saudi Arabia: $60 \%$ of pregnant women were able to name some medications to be avoided during pregnancy. This indicates relatively high levels of knowledge of the risk of using medication during pregnancy [33]. A lower proportion of selfmedication in this current study population may also be partially explained by the relatively healthier group to investigate. Pregnant women in Malang who live in rural areas could rely more on herbal or traditional remedies than modern medicine.

Women with high levels of knowledge of OTC medication in our study were more likely to self-medicate during pregnancy. Because they knew more about the OTC medication, these women may be more likely to manage self-medication responsibly. This result is consistent with those of studies conducted in China [38], Nigeria [18], and India [39]. To propose some possible reasons explaining this phenomenon, first, a higher level of knowledge from prior experiences of self-medication to manage ill symptoms may increase the chance or competence for later practice of self-medication during pregnancy. Second, the faster alleviation of symptoms may also be associated with the use of alternative medication [18]. However, our findings are inconsistent with those of a study conducted in Delta State, Nigeria [37]. Examining the specific use of non-steroidal antiinflammatory drugs (NSAIDs) as their main dependent factor might explain this inconsistency [40].

Two important knowledge statements were separately examined. Consistent with results from a study conducted in Italy [22], pregnant women were observed to be more likely to consult a medical professional before taking OTC medication. Such behavior is healthy and allows medical professionals to impart sound information on the use of medication during pregnancy. Another important observation was of pregnant women being less likely to self-medicate if they knew there were possible risks of taking medication during pregnancy. Imparting specific and crucial information about OTC medication may be more effective to help pregnant women safely manage their practice towards OTC medication.

Previous studies have reported socio-demographic characteristics, such as one's education [18, 41-43], occupation [22, 41-43], health status [44], and household income [41] to be important factors on the likelihood of self-medication. Similarly, we observed that older pregnant women were significantly more likely to selfmedicate, after including other covariates in the logistic regression. Nevertheless, this current study did not observe the significant effects of other socio-demographic characteristics on self-medication. Instead, the moderating effects of socio-demographic characteristics on the association between knowledge and self-medication were 
observed. The effects of a higher level of knowledge on taking at least one type of OTC medication were particularly significant among pregnant women with middle school or lower education $(p<0.05)$. Highly educated pregnant women with high levels of knowledge of the risks of taking OTC medication during pregnancy were less likely to self-medicate.

Our findings have important implications. Imparting specific knowledge of the potential risks of using nonprescribed medication during pregnancy may help pregnant women more safely manage their OTC use. The significant effects of a higher level of knowledge on selfmedication among women with lower income and education levels may indicate a level of their competence that is a strength upon which a provider could build. This study was conducted in primary healthcare services (Puskesmas), a very basic type of healthcare service in Indonesia. Here, knowledge and experiences using OTC medication can be easily shared and spread. Most patients also come from low to middle-income families, especially in the rural area that is Malang Regency. Expanding the role of healthcare providers together with the provision of evidence-based information in prenatal health education is crucial to promote pregnant women's safe management of OTC medication.

Our study is the first to examine self-medication during pregnancy in Indonesia. We identified factors associated with self-medication in the Malang population. To identify vulnerable segments of pregnant women for possible unsafe use of self-medication, we further performed subgroup analyses to examine moderation effects. These women should be targeted in the design and implementation of future health programs.

There are some limitations to this study. First, this study used a convenient sample drawn from the population in Malang area. As the areas selected for investigation may not be representative, the study's results may not be generalized to all pregnant women in Indonesia. Second, the proportion of self-medication in this sample may have been underestimated. This study included women in all trimesters when administering the questionnaire. Thus, the subsequent medication use among women in their early trimester was not recorded in this study. Third, the study's cross-sectional design inhibited causal inference.

\section{Conclusion}

This study observed $11.7 \%$ of women in this convenience sample self-medicated during pregnancy. Knowledge and age were observed to be associated with selfmedication during pregnancy. Our results demonstrated that knowledge of OTC medication in general, and knowledge of the possible risks of taking OTC medication during pregnancy in particular, were strongly associated with the use of self-medication among pregnant women in Malang.

This study can be improved by future studies using either larger cohorts or a case-control method to examine the effects of self-medication on the mother and child's health during pregnancy and postpartum. Based on our findings, we also suggest collecting more data from more healthcare services, such as hospitals, to obtain more findings generalizable to the Indonesian community.

\section{Supplementary information}

Supplementary information accompanies this paper at https://doi.org/10. 1186/s12884-020-2736-2.

Additional file 1. Questionnaire - Self-medication Questionnaire.

Abbreviations

ANC: Antenatal care; aOR: adjusted odd ratio; $\mathrm{Cl}$ : Confidence interval; FDA: Food and Drug Administration; NTD: Neural tube defects; OTC: Overthe-counter; Puskesmas: Pusat kesehatan masyarakat; SPSS: Statistical Packages for Social Sciences

\section{Acknowledgements}

The authors would like to thank the pharmacists who helped with the data collection process in Malang, Indonesia. We would also like to thank all the pregnant women that participated in this study.

Authors' contributions

RNA carried out data collection, data analysis, data interpretation, and drafted the manuscript. ON provided suggestions for manuscript preparation and critically revised the draft of the manuscript. SLY assisted in the data collection process. YHC conceived and designed this study and supervised all critical data analysis and manuscript preparation. All authors read and approved the final manuscript.

Funding

None.

Availability of data and materials

The data used/or analyzed during the current study is available from the corresponding author on a reasonable request.

Ethics approval and consent to participate

The Commission of Research Ethics of the University of Muhammadiyah Malang (E.5.a/226a/KEPK-UMM/VII/2018) provided ethical approval. Informed consent was sought from each respondent about the details of the study at the beginning of the survey. All respondents signed a written informed consent.

Consent for publication

Not applicable.

Competing interests

The authors declare that they have no competing interests.

Author details

${ }^{1}$ Pharmacy Department, Faculty of Health Science, University of Muhammadiyah Malang, Kampus II, Malang, Indonesia. ${ }^{2}$ School of Public Health, College of Public Health, Taipei Medical University, Taipei, Taiwan.

Received: 4 July 2019 Accepted: 10 January 2020

Published online: 16 January 2020

References

1. Lagoy CT, Joshi N, Cragan JD, Rasmussen SA. Report from the CDC: medication use during pregnancy and lactation: an urgent call for public health action. J Women's Health. 2005;14(2):104-9. 
2. Lupattelli A, Spigset O, Twigg MJ, Zagorodnikova K, Mårdby AC, Moretti ME, Drozd M, Panchaud A, Hämeen-Anttila K, Rieutord A, et al. Medication use in pregnancy: A cross-sectional, multinational web-based study. BMJ Open. 2014;4(2):e004365.

3. Bleek W, Asante-Darko NK. Illegal abortion in southern Ghana: methods, Motives and Consequences. Human Organization. 1986;45(4):333-44.

4. Koren G, Florescu A, Costei AM, Boskovic R, Moretti ME. Nonsteroidal antiinflammatory drugs during third trimester and the risk of premature closure of the ductus arteriosus: a meta-analysis. Ann Pharmacother. 2006; 40(5):824-9.

5. Binyam Kebede TGAG. Assessment of drug use among pregnant women in Addis Ababa; 2009. p. 462-8.

6. Kessler DA, Pines WL. The federal regulation of prescription drug advertising and promotion. JAMA. 1990;264(18):2409-15.

7. Yang T, Walker MC, Krewski D, Yang Q, Nimrod C, Garner P, Fraser W, Olatunbosun O, Wen SW. Maternal characteristics associated with pregnancy exposure to FDA category C, D, and X drugs in a Canadian population. Pharmacoepidemiol Drug Saf. 2008;17(3):270-7.

8. Svensson T. Drug use during pregnancy in Sweden - assessed by the Prescribed Drug Register and the Medical Birth Register; 2011. p. 43-50.

9. Hardon A, Van der Geest S, Hardon A. Self-medication in developing countries. J Soc Administr Pharmacy. 1990;7(4):199-204 2015(January 1990).

10. Briggs GG, Freeman RK, Yaffe SJ. Drugs in pregnancy and lactation. 5th ed. Baltimore: Lippincott, Williams \& Wilkins; 2003.

11. Robert E, Guibaud P. Maternal VALPROIC acid and congenital neural tube defects. Lancet. 1982;320(8304):937.

12. Werler MM, Mitchell AA, Hernandez-Diaz S, Honein MA. Use of over-the-counter medications during pregnancy. Am J Obstet Gynecol. 2005;193(3):771-7.

13. Verstappen GM, Smolders EJ, Munster JM, Aarnoudse JG, Hak E. Prevalence and predictors of over-the-counter medication use among pregnant women: A cross-sectional study in the Netherlands. BMC Public Health. 2013;13(1):185.

14. Abduelkarem AR, Mustafa $\mathrm{H}$. Use of over-the-counter medication among pregnant women in Sharjah, United Arab Emirates. J Pregnancy. 2017;2017: 4503793.

15. Cleary BJ, Butt H, Strawbridge JD, Gallagher PJ, Fahey T, Murphy DJ. Medication use in early pregnancy-prevalence and determinants of use in a prospective cohort of women. Pharmacoepidemiol Drug Saf. 2010;19(4): 408-17

16. Abeje G, Admasie C, Wasie B. Factors associated with self medication practice among pregnant mothers attending antenatal care at governmental health centers in Bahir Dar city administration, Northwest Ethiopia, a cross sectional study. Pan Afr Med J. 2015;20:276.

17. Bohio R, Brohi ZP, Bohio F. Utilization of over the counter medication among pregnant women; a cross-sectional study conducted at Isra University hospital, Hyderabad. J Pak Med Assoc. 2016;66(1):68-71.

18. Abasiubong F, Bassey EA, Udobang JA, Akinbami OS, Udoh SB, Idung AU. Self-medication: potential risks and hazards among pregnant women in Uyo, Nigeria. Pan Afr Med J. 2012;13:1-8.

19. Beyene KGM, Beza SW. Self-medication practice and associated factors among pregnant women in Addis Ababa, Ethiopia. Trop Med Health. 2018; 46(1):1-14.

20. Odalovic M, Vezmar Kovacevic S, Nordeng H, llic K, Sabo A, Tasic L. Predictors of the use of medications before and during pregnancy. Int J Clin Pharm. 2013;35(3):408-16.

21. Ebrahimi H, Atashsokhan G, Amanpour F, Hamidzadeh A. Self-medication and its risk factors among women before and during pregnancy. Pan Afr Med J. 2017;27:1-8.

22. Navaro M, Vezzosi L, Santagati G, Angelillo IF. Knowledge, attitudes, and practice regarding medication use in pregnant women in southern Italy. PLoS One. 2018;13(6):1-14.

23. Indonesia Ministry of Health. Undang-undang obat keras:Staatsblad No.419; 22. Jakarta: Indonesia Ministry of Health; 1949.

24. Alfian SD, Sinuraya RK, Kautsar AP, Abdulah R. Consumer expectation on service quality provide by pharmacist in self medication practices and its associated factors in BANDUNG, Indonesia. Southeast Asian J Trop Med Public Health. 2016;47(6):1379-84.

25. Badan Pusat S. Kabupaten Malang Dalam Angka 2017; 2017.

26. Badan Pusat S. Statistik Kesejahteraan Rakyat Kota Malang 2017; 2017.

27. Beyene A, Getachew E, Doboch A, Poulos E, Abdurahman K, Alebachew M. Knowledge, attitude and practice of self medication among pharmacy students of rift Valley University, Abichu campus, Addis Ababa, Ethiopia. J Health Med Informat. 2017:8(269):2.

28. Guillemin F, Bombardier C, Beaton D. Cross-cultural adaptation of healthrelated quality of life measures: literature review and proposed guidelines. J Clin Epidemiol. 1993;46(12):1417-32.

29. Isaac S, Michael WB. Handbook in research and evaluation. San Diego: Educational and Industrial Testing Services; 1995.

30. Sharma D, Gurung D, Kafle R, Singh S. Knowledge and practice on over-thecounter drugs among adults of age group 20 and above residing in Chapapani-12, Pokhara, Kaski, Nepal. Int J Sci Rep. 2017;33(3):79-86.

31. Nkoka O, Chuang T-W, Chen Y-H. Multilevel analysis of factors associated with treatment-seeking behaviors among caregivers with febrile children in Malawi; 2019.

32. Nordeng $H$, Koren $G$, Einarson A. Pregnant women's beliefs about medications - a study among 866 Norwegian women. Ann Pharmacother. 2010;44(9):1478-84.

33. Zaki NM, Albarraq AA. Use, attitudes and knowledge of medications among pregnant women: a Saudi study. Saudi Pharm J. 2014;22(5):419-28.

34. Ceulemans M, Van Calsteren K, Allegaert K, Foulon V. Beliefs about medicines and information needs among pregnant women visiting a tertiary hospital in Belgium. Eur J Clin Pharmacol. 2019;75(7):995-1003.

35. Katz MH. Multivariable analysis: a practical guide for clinicians and public health researchers: Cambridge university press; 2011

36. Nkoka O, Chuang TW, Chen YH. Association between timing and number of antenatal care visits on uptake of intermittent preventive treatment for malaria during pregnancy among Malawian women. Malar J. 2018;17(1):111.

37. Okandeji-Barry RO, Otovwe A, Uju OS. Pharmaceutical Knowledge, Attitude and Use of Non-Prescription Drugs Among Pregnant Women in Okwe General Hospital Asaba Delta State ,Nigeria. Eur J Pharm Med Res. 2016; 3(11):101-10.

38. Yuefeng L, Keqin R, Xiaowei R. Use of and factors associated with selftreatment in China. BMC Public Health. 2012;12(1):995.

39. Selvaraj K, Kumar SG, Ramalingam A. Prevalence of self-medication practices and its associated factors in urban Puducherry, India. Perspect Clin Res. 2014;5(1):32.

40. Kassaw C, Wabe NT. Pregnant women and non-steroidal anti-inflammatory drugs: knowledge, perception and drug consumption pattern during pregnancy in Ethiopia. N Am J Med Sci. 2012;4(2):72.

41. Awad Al, Eltayeb IB, Capps PA. Self-medication practices in Khartoum state, Sudan. Eur J Clin Pharmacol. 2006;62(4):317-24.

42. Devkota R, Khan GM, Alam K, Sapkota B, Devkota D. Impacts of counseling on knowledge, attitude and practice of medication use during pregnancy. BMC Pregnancy Childbirth. 2017;17(1):1-7.

43. Marwa KJ, Njalika A, Ruganuza D, Katabalo D, Kamugisha E. Self-medication among pregnant women attending antenatal clinic at Makongoro health Centre in Mwanza, Tanzania: a challenge to health systems. BMC Pregnancy Childbirth. 2018;18(1):1-9.

44. Lei $X$, Jiang H, Liu C, Ferrier A, Mugavin J. Self-medication practice and associated factors among residents in Wuhan, China. Int J Environ Res Public Health. 2018;15(1):68.

\section{Publisher's Note}

Springer Nature remains neutral with regard to jurisdictional claims in published maps and institutional affiliations.

\section{Ready to submit your research? Choose BMC and benefit from:}

- fast, convenient online submission

- thorough peer review by experienced researchers in your field

- rapid publication on acceptance

- support for research data, including large and complex data types

- gold Open Access which fosters wider collaboration and increased citations

- maximum visibility for your research: over $100 \mathrm{M}$ website views per year

At $\mathrm{BMC}$, research is always in progress.

Learn more biomedcentral.com/submission 